\title{
The Ventral Tegmental Area Is Required for the Behavioral and Nucleus Accumbens Neuronal Firing Responses to Incentive Cues
}

\author{
Irene A. Yun, ${ }^{1,2}$ Ken T. Wakabayashi, ${ }^{1}$ Howard L. Fields, ${ }^{1,3}$ and Saleem M. Nicola ${ }^{1}$ \\ ${ }^{1}$ Ernest Gallo Clinic and Research Center, University of California, San Francisco, Emeryville, California 94608, and ${ }^{2}$ Graduate Program in Neuroscience and \\ ${ }^{3}$ Departments of Neurology and Physiology, and Wheeler Center for the Neurobiology of Addiction, University of California, San Francisco, California 94143
}

\begin{abstract}
Reward-predictive cues exert powerful control over behavioral choice and may be a critical factor in drug addiction. Reward-seeking elicited by predictive cues is facilitated by the release of dopamine in the nucleus accumbens (NAc), yet the contribution of dopamine to the specific NAc firing patterns that underlie goal-directed behavior has remained elusive. We present evidence that subpopulations of NAc neurons that respond to predictive cues require the dopaminergic projection from the ventral tegmental area (VTA) to promote reward-seeking behavior. Rats trained to perform an operant response to a cue to obtain a sucrose reward were implanted with both multiunit recording electrodes in the NAc and microinjection cannulas in the VTA. Both the behavioral response to cues and the cue-evoked firing of NAc neurons were blocked by injection of the $\mathrm{GABA}_{\mathrm{B}}$ agonist baclofen into the VTA. An additional group of rats was trained on the same task and then implanted with microinjection cannulas in the NAc. Like VTA baclofen injection, injection of dopamine receptor antagonists into the NAc profoundly reduced cue-elicited reward seeking. Together, these results support the conclusion that both the behavioral response to the cue and the specific NAc neuronal firing that promotes the response depend on dopamine release within the NAc. Our findings suggest a neural mechanism by which the dopamine-dependent firing of NAc neurons mediates goaldirected behavior.
\end{abstract}

Key words: dopamine; motivation; operant; reward; goal-directed behavior; nucleus accumbens; basal ganglia; ventral striatum; discriminative stimulus

\section{Introduction}

Elucidating the actions of dopamine on nucleus accumbens (NAc) neurons is essential for understanding motivated behaviors. Reward-predictive cues trigger reward seeking, activate dopamine neurons (Ljungberg et al., 1992; Schultz et al., 1993), and cause NAc dopamine release (McCullough and Salamone, 1992; Bassareo and Di Chiara, 1999; Weiss et al., 2000; Robinson et al., 2001, 2002; Roitman et al., 2004). These findings suggest that a dopamine-induced change in NAc neuronal firing signals that a stimulus is motivationally salient and increases the probability of a behavioral response (Berridge and Robinson, 1998). In support of this idea, reducing NAc dopamine function inhibits reward seeking in response to reward-associated cues (Blackburn et al., 1992; Di Ciano et al., 2001; Wakabayashi et al., 2004), whereas augmenting NAc dopamine transmission increases operant re-

Received Aug. 27, 2003; revised Feb. 9, 2004; accepted Feb. 9, 2004.

This work was supported by funds provided by the State of California for medical research on alcohol and substance abuse through the University of California, San Francisco, by the Wheeler Center for the Neurobiology of Addiction, by the Ernest Gallo Clinic and Research Center, by National Institute on Drug Abuse Grants DA05832 (S.M.N.) and DA01949 and NS21445 (H.L.F.), and by a National Science Foundation Predoctoral Training Consortium in Affective Science fellowship (I.A.Y.). We thank Drs. W. Chang and V. Kharazia for help with the histology and Drs. G. Hjelmstad, M. Dallman, and P. Janak for insightful discussions.

Correspondence should be addressed to Saleem Nicola, Ernest Gallo Clinic and Research Center, University of California, San Francisco, 5858 Horton Street, Suite 200, Emeryville, CA 94608. E-mail: nicola@phy.ucsf.edu. D01:10.1523/JNEUROSCI.5282-03.2004

Copyright $\odot 2004$ Society for Neuroscience $\quad$ 0270-6474/04/242923-11\$15.00/0 sponding elicited or maintained by reward-associated cues (Taylor and Robbins, 1986; Wolterink et al., 1993; Wyvell and Berridge, 2000). Although NAc dopamine appears critical for goaldirected behavioral responses to predictive cues, it is not yet known which NAc neurons are modulated by dopamine during reward seeking and how this modulation facilitates goal-directed behavior.

NAc neurons in behaving animals exhibit phasic excitations and inhibitions time locked to many task events, such as operant behavior and reward consumption (Apicella et al., 1991; Schultz et al., 1992; Carelli and Deadwyler, 1994; Chang et al., 1994; Peoples and West, 1996; Nicola and Deadwyler, 2000; Nicola et al., 2004a,b). Additional subpopulations are excited or inhibited by reward-predictive cues, suggesting that cue-evoked firing changes in NAc neurons contribute to cue-elicited behavioral responses. For instance, in primate ventral striatum, cue-evoked excitations depend on the magnitude and type of reward predicted by the cue and the temporal proximity of reward (Bowman et al., 1996; Hollerman et al., 1998; Shidara et al., 1998; Hassani et al., 2001; Cromwell and Schultz, 2003). In rat NAc neurons, cueevoked excitations and inhibitions (incentive cue excitations and inhibitions) are larger for reward-predictive than for nonpredictive cues (Ghitza et al., 2003; Nicola et al., 2004a) and larger when the animal makes a behavioral response to the cue (Nicola et al., 2004a). The possibility that cue-evoked firing of NAc neu- 
rons depends on dopamine suggests a specific means of testing the hypothesis that these firing patterns are required for the behavioral response. NAc incentive cue excitations and inhibitions begin at approximately the time that midbrain dopamine neurons are excited by such cues. Furthermore, in well trained animals performing cue-response tasks, the dopamine neuron response is not correlated with either reward acquisition or operant behavior (Ljungberg et al., 1992; Schultz et al., 1993), nor is it evoked by cues that do not predict reward (Mirenowicz and Schultz, 1994). Therefore, it is likely that dopamine selectively modulates responses to reward-predictive cues. If this is the case, then removing the dopamine input to the NAc should reduce the cue-evoked excitation and/or inhibition of NAc neurons. Furthermore, if these excitations and inhibitions are required for reward seeking in response to predictive cues, then interruption of the dopaminergic input to the NAc should also reduce the behavioral response to such cues. In fact, we find that both the cue-evoked firing of NAc neurons and the behavioral response to cues were concomitantly abolished by localized injection of baclofen into the ventral tegmental area (VTA). In addition, we present evidence to localize the effect of reduced dopamine to the NAc by showing that blockade of dopamine receptors in the NAc reduces cue-elicited behavior.

\section{Materials and Methods}

Two experiments were performed, involving two separate groups of rats. First, we conducted a behavioral study in which we trained animals on a discriminative stimulus (DS) task, implanted microinjection cannulas in the NAc, and determined how dopamine antagonists injected in the NAc affected responding to predictive cues during the DS task. Next, we used a subset of the rats from our previous electrophysiological studies (Nicola et al., 2004a,b) to determine whether VTA baclofen injection concomitantly affected behavior on the DS task and the firing of NAc neurons. These animals received, in the same surgery, both recording electrodes in the NAc and microinjection cannulas in the VTA.

For both experiments, the subjects were male Long-Evans rats [Harlan Sprague Dawley (Indianapolis, IN) or Charles River Laboratories (Wilmington, MA)], which weighed $\sim 350$ gm on arrival. They were individually housed on a $12 \mathrm{hr}$ light/dark cycle; experiments were conducted during the light phase. After receipt, rats were allowed at least 1 week of ad libitum food and water, followed by 1 week of restricted food and water before training. Throughout all experiments (both behavioral and electrophysiological), restriction was accomplished by allowing the animals $1 \mathrm{hr}$ of ad libitum food and water per day, at the end of experimental manipulations. Animal handling and experiments conformed to National Institutes of Health and Ernest Gallo Clinic and Research Center animal care and use policies.

Behavioral study (NAc microinjection). Rats $(n=12)$ were trained on the DS task exactly as described by Nicola et al. (2004a). The task is diagrammed in Figure 1. Standard operant chambers $(23.5 \times 30.5 \mathrm{~cm})$ contained two nose pokes, one on each side of a reward receptacle, two houselights, a white-noise speaker, and a tone speaker (Med Associates, St. Albans, VT). Liquid 10\% sucrose reward was delivered into a well in the reward receptacle by a syringe pump. In the DS task, the DS was presented on a variable interval schedule with an average interval of 2 $\mathrm{min}$. The DS consisted of an intermittent tone (200 msec tone-on intervals, $550 \mathrm{msec}$ tone-off intervals) coupled with dimmed houselights (by turning off one of the two). Each DS presentation lasted up to $20 \mathrm{sec}$. If the animal responded to the DS by making a nose poke in the active nose-poke hole, the DS was terminated, $50 \mu \mathrm{l}$ of $10 \%$ sucrose was delivered into the reward receptacle, and a $20 \mathrm{sec}$ conditioned stimulus (CS) was presented. The CS consisted of an $8 \mathrm{kHz}$ intermittent tone $(200 \mathrm{msec}$ on, $550 \mathrm{msec}$ off) with continued dimmed houselights. In addition to the DS, a non-rewarded stimulus (NS) was presented on an independent variable interval $2 \mathrm{~min}$ schedule. The NS also consisted of an intermittent tone (200 msec on, $550 \mathrm{msec}$ off) and dimmed houselights. For six rats,

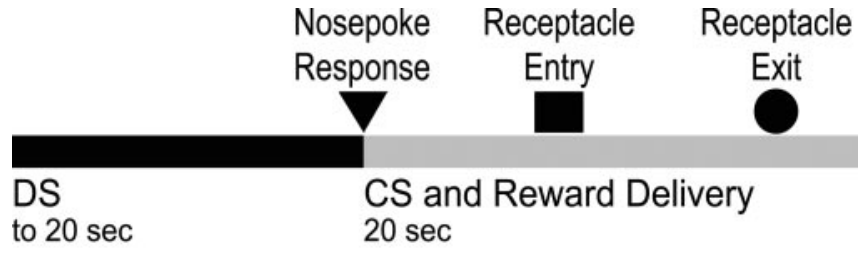

\section{NS}

$20 \mathrm{sec}$

Figure 1. Diagram of the DS task. Two cues were presented on independent variable interval 2 min schedules. If the animal responded to the DS by performing a nose poke, $10 \%$ sucrose reward was delivered into a reward receptacle located near the nose poke. ACS was presented for $20 \mathrm{sec}$ after a successful response to the nose poke. Animals remained in the reward receptacle for $\sim 9$ sec after entering it to consume reward. Responding to the NS was not rewarded.

the DS tone was $6 \mathrm{kHz}$ and the NS tone was $4 \mathrm{kHz}$, and, for the remaining six rats, the DS was $4 \mathrm{kHz}$ and the NS was $6 \mathrm{kHz}$. Responding during the $\mathrm{NS}$, the CS, or in the absence of the DS was never rewarded. Animals were given one $2 \mathrm{hr}$ session per day.

When animals were trained to criterion performance ( $>90 \%$ DS response ratio, defined as the proportion of all DSs in the session to which the animal responded), they were stereotaxically implanted with microinjection cannulas in the NAc. Anesthesia was induced with ketamine and xylazine (intraperitoneally) and maintained with isoflurane. Target coordinates of the injection cannulas were as follows (in mm relative to bregma): anteroposterior (AP), 1.6; mediolateral (ML) \pm 1.1 ; dorsoventral (DV), -7.5 . Guide cannulas were 26 ga double cannulas separated by $2.2 \mathrm{~mm}$ (Plastics One, Roanoke, VA). Obturators flush with the bottom of the guide cannulas were inserted and remained in place at all times except during drug injection. The guide cannulas were secured to the skull with dental acrylic and bone screws. Animals were allowed 1 week to recover before retraining to criterion.

After retraining, animals received one of seven injections before behavioral testing sessions. Each injection session was followed and preceded by a recovery session in which no drugs were injected. Three different doses of the $\mathrm{D}_{1}$ antagonist $\mathrm{SCH} 23390$ and the $\mathrm{D}_{2}$ antagonist raclopride (Sigma, St. Louis, MO) were injected. For SCH23390, these were 1,2 , and $4 \mu \mathrm{g} / \mathrm{side}$. For raclopride, these were 2, 4 , and $6 \mu \mathrm{g} / \mathrm{side}$. Drugs were dissolved daily in saline and injected bilaterally in a volume of $500 \mathrm{nl} /$ side. A vehicle control injection was also given. The order of the seven injections was randomized and different for each rat. In the injection procedure, the animal was gently restrained while the obturators were removed and the injection cannulas were inserted into the guides. After a $1 \mathrm{~min}$ wait, the total volume was injected over $2 \mathrm{~min}$ by a programmable syringe pump. After an additional $1 \mathrm{~min}$ wait, the injection cannulas were removed, the obturators were replaced, the animal was immediately placed in the behavioral chamber, and the session was started.

To analyze the behavioral data, the measured parameters (DS response ratio, NS response ratio, and latency to respond to the DS) were compared across drug doses using one-way within-subjects ANOVA. We also examined the time course of the drug effects over the behavioral session by using two-way within-subjects ANOVA, with one factor being drug dose and the other the time since the start of the session (broken into 20 min bins) (see Fig. $2 J, K$ ).

Electrophysiological study (NAc recording and VTA baclofen injection). A subset of 14 of the animals described in our previous studies (Nicola et al., 2004a,b) was used for this experiment. Animals were trained exactly as described in the previous papers and were run on a DS task that was identical to the one described above for the behavioral study, with two exceptions. First, for the electrophysiology-VTA baclofen injection study, the operant chambers were larger $(40.6 \times 40.6 \mathrm{~cm})$, and second, for most animals, the sucrose reward was delivered with a dipper instead of a syringe pump.

Fully trained animals received both microwire recording electrodes 
Table 1. Summary of analysis windows and results

\begin{tabular}{|c|c|c|c|c|c|c|c|c|}
\hline Neuronal response type & Analysis window & $n$ & $\begin{array}{l}\text { Baseline firing rate, } \\
\text { preinjection }(\mathrm{Hz})\end{array}$ & $\begin{array}{l}\text { Baseline firing rate, } \\
\text { post-baclofen }(\mathrm{Hz})\end{array}$ & $p$ & $\begin{array}{l}\text { Excitation or } \\
\text { inhibition, } \\
\text { preinjection }(\mathrm{Hz})\end{array}$ & $\begin{array}{l}\text { Excitation or } \\
\text { inhibition, } \\
\text { post-baclofen }(\mathrm{Hz})\end{array}$ & $p$ \\
\hline Incentive cue excitation & $0-1$ sec after DS & 8 & 3.0 & 1.3 & $0.04^{*}$ & 6.1 & 0.3 & $<0.001$ \\
\hline Incentive cue inhibition & $0-1$ sec after DS & 10 & 2.1 & 1.0 & 0.07 & 1.0 & 0.2 & 0.007 \\
\hline Operant excitation & $1-0$ sec before nose poke & 12 & 2.8 & 2.1 & 0.05 & 4.0 & 2.7 & 0.2 \\
\hline Operant inhibition & Nose poke to recept. entry & 16 & 2.3 & 1.1 & 0.01 & 1.1 & 1.2 & $0.003^{*}$ \\
\hline Receptacle entry excitation & $0.5-0$ sec before recept. entry & 12 & 2.2 & 1.8 & 0.6 & 2.4 & 2.0 & 0.2 \\
\hline Sustained receptacle excitation & $1-5$ sec after recept. entry & 10 & 2.4 & 1.8 & 0.2 & 2.8 & 0.3 & 0.3 \\
\hline Sustained receptacle inhibition & $1-5$ sec after recept. entry & 26 & 1.8 & 1.6 & 0.2 & 1.1 & 1.1 & 0.3 \\
\hline Receptacle exit excitation & $0-1$ sec after recept. exit & 9 & 2.4 & 2.9 & 0.6 & 2.5 & 0.4 & 0.03 \\
\hline
\end{tabular}

The analysis window is the section of the perievent histogram used to compute excitation or inhibition relative to the 10 sec pre-DS baseline. $n$ values are the numbers of neurons used to analyze the effects of behaviorally effective VTA baclofen injections on the indicated response type. All firing rates, excitations, and inhibitions are median values across neurons. Baseline firing rate refers to the 10 sec pre-DS baseline firing rate, which was averaged across all preinjection and post-baclofen DS presentations for each neuron. $p$ values are the results of ranks-based within-subjects ANOVAs comparing firing rate (or excitation or inhibition) before injection, after behaviorally effective VTA baclofen injection, and during behavioral recovery. For brevity, firing values during recovery are not shown. The first column of $p$ values shows the results of comparisons of baseline firing rates, and the second column of $p$ values shows the results of comparisons of excitations or inhibitions. Comparisons with a significant ANOVA result and significant Student-Newman-Keuls comparison between preinjection and post-baclofen conditions are indicated in bold. * indicates that, although the overall ANOVA effect was significant, post hoc Student-Newman-Keuls tests showed no significant difference between the two conditions. recept., Receptacle.

(described in detail by Nicola and Deadwyler, 2000; Nicola et al., 2004a) implanted in the NAc and guide cannulas for microinjection in the VTA during the same stereotaxic surgery. Arrays (NB Labs, Denison, TX) consisted of two parallel rows of four electrodes (eight electrodes total per array; electrode diameter, $50 \mu \mathrm{m}$ ) and were $\sim 0.7 \mathrm{~mm}$ long and $0.3 \mathrm{~mm}$ wide. They were implanted bilaterally with the long dimension in the saggital plane. Target coordinates of the medioposterior electrode were as follows (in mm relative to bregma): $\mathrm{AP}, 1.0 ; \mathrm{ML}, \pm 0.5 ; \mathrm{DV},-6.5$ to -8 . Target coordinates of the VTA injection cannulas were as follows (in $\mathrm{mm})$ : AP, -4.5 to -5.0 ; ML, \pm 0.25 to \pm 0.5 ; DV,-7.8 to -9.5 . Cannulas were placed in the rostral VTA because, compared with caudal VTA, the activity of rostral VTA neurons appears to contribute preferentially to reinforcement (Ikemoto et al., 1998; Carlezon et al., 2000). Guide cannulas were 27 ga stainless steel tubes. They were implanted at an angle of $\sim 10^{\circ}$ from vertical in the coronal plane, to allow the experimenters access to both the electrode connectors and the cannulas. Obturators $(0.38$ $\mathrm{mm}$ stainless steel wire) were inserted and remained in place at all times except during injection. The electrodes and cannulas were secured to the skull with dental acrylic and bone screws. Animals were allowed to recover from surgery for 1 week before commencement of experiments.

Electrophysiological recording was conducted as described previously (Nicola et al., 2004a). Animals were connected to the recording apparatus [consisting of a head stage with field effect transistors, cable, commutator to allow the animal free movement within the chamber, and Plexon Inc. (Dallas, TX) spike sorting hardware and software], and units were isolated as described previously. A 60-90 min baseline recording session, during which animals were allowed to perform the DS task, was run every day for each rat ( $5 \mathrm{~d} /$ week). At the end of the baseline session, animals were removed from the behavior-recording chamber and injected with $100 \mathrm{nl}$ of saline or (+)baclofen into the VTA. Injections were made over $1 \mathrm{~min}$, with a $1 \mathrm{~min}$ postinjection wait before removal of the injector. After the injection, the animals were immediately reconnected to the recording apparatus and placed in the chamber for the postinjection session. This lasted at least $2 \mathrm{hr}$ or until behavioral recovery. Recovery was defined as regular behavioral responding to the DS. Fresh baclofen stock solution was dissolved in saline weekly or more frequently.

Although most VTA injections were unilateral, the VTA straddles the midline (cannulas were placed accordingly), and the injected drug was likely to affect both hemispheres. Bilateral injections were made in some cases but were not included in the dose-response analysis of behavior shown in Figure 2. They were, however, included in the analysis of the effects of VTA baclofen injection on the firing of NAc neurons. Unilateral injections alternated daily between the implanted cannulas, and the dose was adjusted each day to determine a dose that resulted in transient but pronounced behavioral effects that recovered within the postinjection session. The result was that many different doses were administered, which allowed us to construct the dose-response curves shown in Figure 2. However, not enough neurons of each class were recorded in each dose range for an accurate dose-response analysis of the effects of VTA baclofen on NAc neuronal firing. Nevertheless, the question we wanted to investigate was whether there was a significant effect on firing that paralleled a reduction in behavioral responding to the DS. Therefore, each postinjection session was determined to be either the result of a "behaviorally effective" injection or a "behaviorally ineffective" injection. This determination was based on whether the animal's DS response ratio (the proportion of DSs presented to which the animal made a nose-poke response) was reduced by VTA injection to $<50 \%$ (effective) or remained at $>50 \%$ (ineffective) after the injection. Although higher doses tended to be effective, effective injections also often resulted from the lower baclofen doses, and ineffective injections sometimes resulted from higher doses. Therefore, dividing the sessions into those with behaviorally effective and ineffective injections provided us with an independent criterion for choosing sessions to analyze the effects of VTA baclofen injection on NAc neuronal firing. Analysis of NAc firing after behaviorally effective injections regardless of the dose of baclofen minimized the variability introduced by differences in injection site, possible clogging of the cannula, and backflow of injectate along the cannula track, all of which could potentially reduce the effectiveness of the injections.

With the microwire technique, electrodes are fixed at the time of surgery and cannot be moved subsequently by the experimenter. Microwire recordings are usually quite stable, and thus the same neuron can often be recorded for several days on the same wire. In cases in which the waveform of a neuron was similar on consecutive days, the spike firing data from the neuron was averaged across days provided that the neuron maintained its phasic response in the preinjection baseline period. When a neuron was lost to the noise, neurons recorded subsequently from the electrode that displayed the same response type were not used for analysis. This eliminates the possibility that a single neuron could have contributed $n>1$ to any given analysis.

The neurons used for each analysis were those that exhibited the response type of interest in the preinjection condition. The magnitude of event-related excitation of each neuron during the preinjection period was computed by taking the average firing rate in the window of interest (for a list of analysis windows for each response type, see Table 1) and subtracting the average firing rate during the $10 \mathrm{sec}$ pre-DS baseline. (The magnitude of event-related inhibition was computed by subtracting the firing rate in the window of interest from the pre-DS baseline.) This was repeated for each condition (preinjection, postinjection, and recovery). The excitation or inhibition of each neuron in each of these conditions was used to compute the median excitation or inhibition across neurons in each condition. The median excitations or inhibitions in each condition were then compared with nonparametric within-subjects ANOVA or paired Wilcoxon signed rank tests. A separate ANOVA was used to compare baseline firing rates in the $10 \mathrm{sec}$ before each DS presentation across conditions. Nonparametric tests were used because the firing rates of NAc neurons were not normally distributed.

Histology. Animals were deeply anesthetized with Euthasol and then perfused first with saline and 10\% Formalin. Electrode placements were determined by passing a current through each electrode before perfusion to deposit iron at the tip and completing the perfusion with potassium 
ferrocyanide solution to develop the Prussian blue deposit (Nicola et al., 2004b). Cannula placements were verified by injection of methylene blue or by deposition of iron through an electrode cut to the same length as the injection cannulas and developing the Prussian blue deposit. Brain sections $(40 \mu \mathrm{m})$ were cut on a microtome. NAc and VTA sections were stained with neutral red. In some cases, alternate VTA sections were immunostained with antityrosine hydroxylase antibody to visualize dopamine-containing neurons.

\section{Results \\ Behavior}

In all experiments, the behavioral task performed by the animal was that described in Figure 1. Figure 2 shows that the behavioral effects of VTA baclofen injection are similar to those of NAc dopamine antagonism. We used the $\mathrm{GABA}_{\mathrm{B}}$ agonist baclofen to reduce dopamine neuron firing because injection of baclofen into the VTA strongly reduces NAc dopamine release (Tanner, 1979; Westerink et al., 1996) because of its inhibition of dopamine neurons (Lacey et al., 1988, 1989; Johnson and North, 1992; Seutin et al., 1993; Erhardt et al., 2002). VTA injections were made after we obtained a baseline behavioral and electrophysiological session, and therefore we compared the effects of VTA baclofen injection with both preinjection and saline controls. The postinjection effects were measured in the first $1 \mathrm{hr}$ after the injection. Recovery from the injection usually required 2-3 hr.

Baclofen injection in the VTA dose dependently reduced the proportion of DSs to which the animal responded with a nose poke (Fig. 2A, DS Response Ratio). Two-way within-subjects ANOVA revealed significant effects of dose $\left(F_{(3,70)}=6.8 ; p<\right.$ 0.001 ) and condition (i.e., preinjection or postinjection; $F_{(1,70)}=$ $148, p<0.001)$, as well as a significant interaction $\left(F_{(3,70)}=17\right.$; $p<0.001$ ). Post hoc Student-Newman-Keuls (SNK) tests showed that each postinjection response ratio was smaller than the preinjection response ratio $(p<0.05)$; however, the effect was small for saline and grew progressively larger with increasing doses of baclofen. SNK tests further showed that no preinjection response ratio differed significantly from any other preinjection ratio, whereas the postinjection response ratio at each dose of baclofen differed significantly from the response ratio in all other doses and saline.

Similar effects were observed for the NS response ratio (Fig. $2 \mathrm{D})$. Under control conditions, animals responded to $\sim 50 \%$ of NS presentations. This is somewhat higher than would be expected given that responding to the NS did not result in reward delivery; however, the DS and NS were physically very similar, and this high NS response ratio was likely a result of stimulus generalization (Nicola et al., 2004a). Therefore, it is not surprising that VTA baclofen injection reduced NS responding, similar to the effects on DS responding. ANOVA revealed no significant overall effect of dose $\left(F_{(3,70)}=1.7 ; p>0.1\right)$; however, there was a significant effect of condition (preinjection vs postinjection; $\left.F_{(1,70)}=69 ; p<0.001\right)$ and a significant interaction between dose and condition $\left(F_{(3,70)}=4.6 ; p<0.01\right)$. Post hoc SNK tests indi- cated that all postinjection NS response ratios were significantly lower than their corresponding preinjection ratios $(p<0.05)$. None of the preinjection ratios differed significantly, but after injection of the two highest baclofen doses, the NS response ratios were significantly lower than the post-saline ratios $(p<0.05)$.

The latency to respond to the DS with a nose poke was increased by VTA baclofen injection (Fig. 2G). Although ANOVA showed no overall effect of dose $\left(F_{(3,60)}=2.0 ; p>0.1\right)$, there was a significant effect of condition $\left(F_{(1,60)}=38 ; p<0.001\right)$ and a significant interaction between condition and dose $\left(F_{(3,60)}=10\right.$; $p<0.001)$. Post hoc SNK analysis revealed that injection of each baclofen dose resulted in significantly higher latencies after injection compared with before $(p<0.05)$, whereas saline injection had no significant effect. None of the preinjection latencies significantly differed, but after injection of the lowest baclofen dose, the latency was significantly higher than after saline injection $(p<0.05)$.

Because VTA dopamine neurons project to the NAc, we sought to determine whether the effects of VTA baclofen injection could have been attributable to reduced dopamine release within the NAc. If this hypothesis is correct, then antagonism of NAc dopamine receptors should mimic the behavioral effects of VTA baclofen injection. Animals trained on the same DS task as that used for the VTA baclofen injection-NAc recording experiments were implanted with NAc cannulas and (after recovery and retraining) were injected with saline, the $D_{1}$ antagonist $\mathrm{SCH} 23390$, or the $\mathrm{D}_{2}$ antagonist raclopride before the start of the behavior session. We first computed the DS response ratio, NS response ratio, and DS response latency across the entire $2 \mathrm{hr}$ session. The $\mathrm{D}_{1}$ antagonist dose dependently reduced responding to the DS $\left(F_{(8,86)}=83.5 ; p<0.001\right)$ (Fig. $\left.2 B\right)$ and NS $\left(F_{(8,86)}=\right.$ 


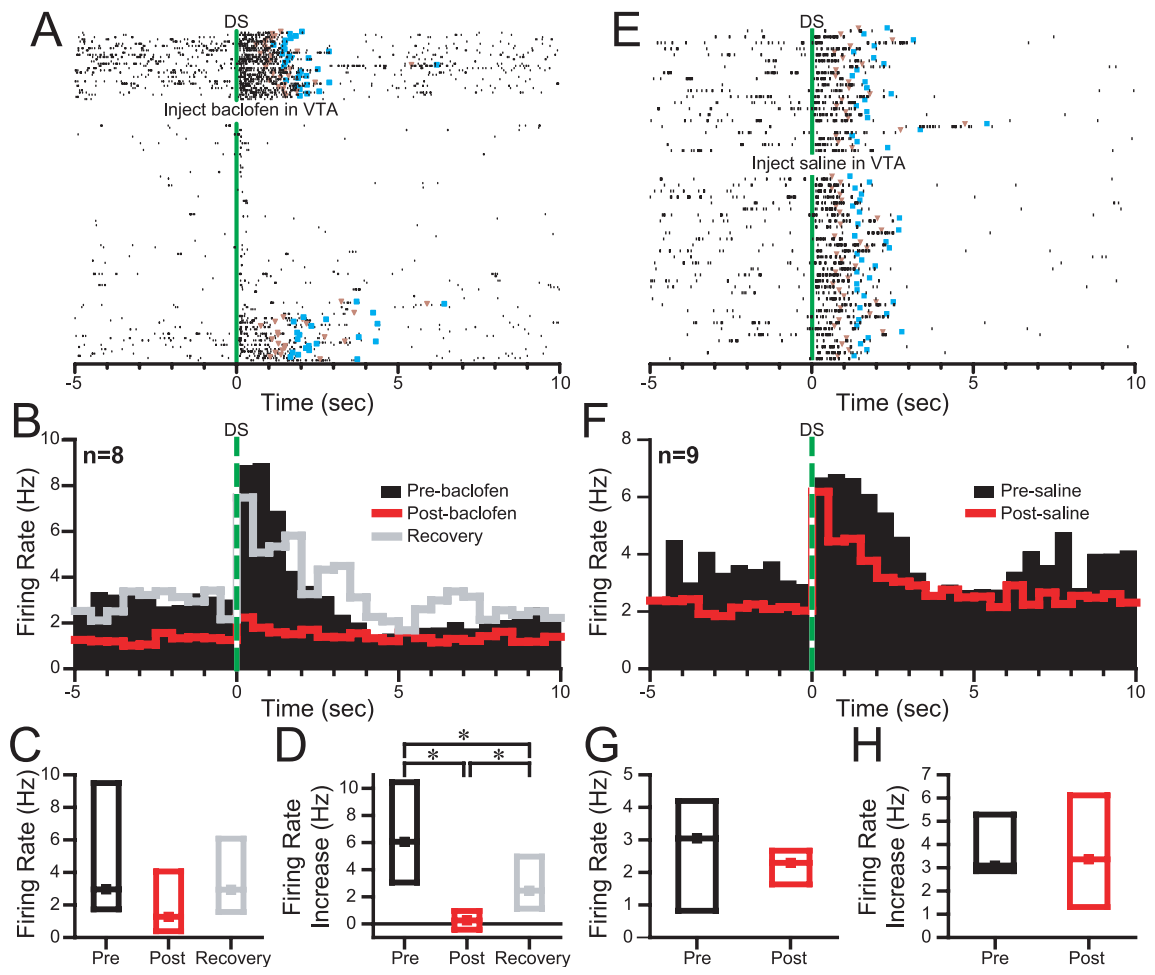

Figure 3. Behaviorally effective VTA baclofen injection reduces the DS-evoked excitation of NAc neurons with incentive cue excitation. $A$, Raster plot showing the effects of VTA baclofen on an NAc neuron with incentive cue excitation. The rasters are time locked to DS presentation and are sorted from top to bottom by time since the start of the session. VTA baclofen injection reduces the pre-DS baseline firing rate of this neuron as well as its DS-evoked excitation. Orange triangles indicate the time at which the nose poke occurred, and blue squares indicate the reward receptacle entry. $B$, Each bin in the perievent histograms shows the median firing rate of all neurons with incentive cue excitations that were subjected to the three conditions: preinjection (black histogram), postinjection (red histogram), and behavioral recovery (gray histogram). Histograms are all time locked to DS presentation. C, Box plots show the median (dot) and first and third quartiles (top and bottom box edges) of the baseline firing rate of the neurons shown in $B$ under the three conditions. $D$, Box plots show the median DS-evoked excitation under the three conditions. E, A typical incentive cue excitation before and after saline injection in the VTA.F, Histograms show the median firing rate across all neurons with incentive cue excitation that were recorded before and afterVTA saline injection. G, Box plots show that the baseline firing rate was similar before and after VTA saline. $H$, The median DS-evoked excitation was also similar before and after VTA saline. * $p<0.05$ (SNK test). The width of bins in the perievent histograms in this and all subsequent figures is $500 \mathrm{msec}$.

35.8; $p<0.001$ ) (Fig. $2 E$ ) and increased the DS response latency $\left(F_{(8,86)}=11.3 ; p<0.001\right)$ (Fig. $\left.2 H\right)$. These effects were remarkably similar to those of VTA baclofen injection (Fig. $2 A, D, G$ ). The $\mathrm{D}_{2}$ antagonist also reduced the DS response ratio $\left(F_{(8,76)}=\right.$ $10.2 ; p<0.001)$ (Fig. $2 C$ ) and NS response ratio $\left(F_{(8,76)}=10.7\right.$; $p<0.001$ ) (Fig. $2 F$ ) and increased the DS response latency $\left(F_{(8,76)}=8.2 ; p<0.001\right)$ (Fig. $\left.2 I\right)$.

The $\mathrm{D}_{2}$ antagonist effects were smaller than the $\mathrm{D}_{1}$ antagonist effects and did not appear to be dose dependent. However, raclopride rapidly diffuses from the injection site (Ahlenius et al., 1990), and therefore we examined the time course of the effects of dopamine antagonists on DS response ratio. Sessions were divided into six bins ( $20 \mathrm{~min}$ each), and the response ratio was computed in each bin. The results were analyzed with two-way within-subjects ANOVA. For the $\mathrm{D}_{1}$ antagonist SCH23390 (Fig. $2 J$ ), there were significant overall effects of bin (i.e., time since the start of session $)\left(F_{(5,165)}=17 ; p<0.001\right)$ and dose $\left(F_{(3,165)}=44\right.$; $p<0.001)$, as well as a significant interaction $\left(F_{(15,165)}=3.3 ; p<\right.$ 0.001). Post hoc SNK tests showed that, at all time points, all SCH23390 doses significantly reduced the response ratio compared with the saline control ( $p<0.05$ ). SCH23390 effects were maximal during the first $1 \mathrm{hr}$ of the session and began to recover slowly during the second hour. In contrast, the effects of the $\mathrm{D}_{2}$ antagonist raclopride were much more transient (Fig. $2 K$ ). ANOVA showed significant overall effects of bin $\left(F_{(5,135)}=20\right.$; $p<0.001)$ and dose $\left(F_{(3,135)}=6 ; p<\right.$ $0.005)$, as well as a significant interaction $\left(F_{(15,135)}=3.4, p<0.001\right)$. SNK analyses revealed that, at all doses of raclopride, the response ratio was significantly lower in the first two bins compared with saline; no significant difference from saline was observed for any dose in the last four bins. Interestingly, in the first bin, all raclopride doses caused profound reductions in DS responding similar in magnitude to those seen for the highest doses of SCH23390. Therefore, although $\mathrm{D}_{2}$ receptor antagonism of the NAc had effects similar to those of $\mathrm{D}_{1}$ antagonism, the $\mathrm{D}_{2}$ antagonist effects were more transient, most likely because of the different pharmacokinetic properties of the two drugs.

In summary, these results indicate that both $D_{1}$ and $D_{2}$ receptor activation is essential for NAc neurons to facilitate a behavioral response to cues. They also support the hypothesis that the effects of VTA baclofen injection on DS responding are attributable, at least in part, to the reduction of dopamine release within the NAc.

\section{Electrophysiology}

In previous reports, we described phasic excitations and inhibitions of rat NAc neuronal firing as rats performed the DS task. These occurred in association with different discrete events during the task: DS presentation, operant response, reward receptacle entry, reward consumption, and exit from the reward receptacle (Nicola et al., $2004 a, b)$. One or more of these phasic firing patterns may facilitate the specific behavioral actions required to obtain reward in response to the DS. Thus, the behavioral deficits in cue responding observed after VTA baclofen injection or treatment of the NAc with dopamine antagonists could have been attributable to dopamine dependence of one or a combination of these firing patterns. To determine which firing patterns may be dopamine dependent and required for behavioral responding to cues, we recorded from NAc neurons before and after microinjection of baclofen into the VTA.

\section{Incentive cue excitations and inhibitions}

Incentive cue excitations began almost immediately after DS presentation and often lasted until the animal obtained the reward. These excitations were larger for the DS than the NS and larger when the animal made an operant response than when none was made (Nicola et al., 2004a). As shown in the example in Figure $3 A$, baclofen injections that reduced the DS response ratio to $<50 \%$ (behaviorally effective injections; see Materials and Methods) profoundly reduced the DS-evoked firing of neurons with incentive cue excitations. The loss of the incentive cue excitation and its subsequent recovery were correlated with the loss and recovery of the animal's behavioral response to the DS (Fig. 3A), The effects of VTA baclofen injection on incentive cue-excited 
neurons are summarized across eight neurons in the median histogram (showing the median firing rate across neurons in each bin) in Figure $3 B$. The median baseline firing rates trended toward a significant reduction (Fig. 3C; Table 1), whereas the reduction in median DS-evoked excitation during behaviorally effective VTA baclofen injection was highly significant and partially recovered during behavioral recovery (Fig. 3D; Table 1 ). In contrast, in the nine neurons recorded before and after VTA saline injection, no significant effects on either baseline firing rate or DS-evoked excitation were observed ( $p>0.1$ for excitation; $p>0.09$ for baseline firing rate) (Fig. 3E-H). These results were based on 1 sec post-DS analysis windows; similar results were obtained using $3 \mathrm{sec}$ post-DS windows $(p<0.01$ for the effects of baclofen the excitation; $p>0.09$ for the effects of saline on the excitation).

Behavioral responding to the NS as well as the DS was significantly reduced by VTA baclofen injection and NAc dopamine antagonism (Fig. 2). Neurons with incentive cue excitations were also excited by NS presentation, although the NSevoked excitation was smaller than the DSevoked excitation (Nicola et al., 2004a). If these neurons promote the behavioral response to the NS, their NS-evoked excitation should be smaller after VTA baclofen, as it was for DS-evoked excitation. This was confirmed by within-subjects ranks ANOVA comparing NS-evoked excitation before injection (median excitation, $2.2 \mathrm{~Hz}$ ), during behaviorally effective VTA baclofen injection $(0.04 \mathrm{~Hz})$, and during behavioral recovery $(0.5 \mathrm{~Hz})$, which found that the excitation before and after the injection differed significantly $(p<0.005 ; n=8)$.

Except for their opposite sign, incentive cue inhibitions are similar in most respects to incentive cue excitations: the inhibition begins immediately after DS onset and is characteristically sustained until the animal obtains the reward. Also, the inhibition is smaller when the cue does not elicit a nose-poke response and smaller for the NS than for the DS (Nicola et al., 2004a). Incentive cue inhibitions were profoundly reduced by behaviorally effective VTA baclofen injection (Fig. 4). In 10 neurons, the magnitude of the inhibition was significantly reduced after VTA baclofen (Fig. $4 B, D$; Table 1), whereas the baseline firing rate showed a trend toward a reduction (Fig. $4 B, C$; Table 1 ). In contrast, injection of saline into the VTA had no significant effects in nine neurons ( $p>0.1$ for inhibition; $p>0.09$ for baseline firing rate) (Fig. $4 E-H)$. Similar results were obtained when $3 \mathrm{sec}$ post-DS analysis windows were used ( $p<0.05$ for the effect of baclofen on the inhibition; $p>0.6$ for the effect of saline). We asked whether the inhibition in response to the NS was also reduced by behaviorally effective VTA baclofen injection. The median NS-evoked inhibition was $0.5 \mathrm{~Hz}$ before the injection, -0.05 $\mathrm{Hz}$ after the injection, and $0.2 \mathrm{~Hz}$ during recovery. Ranks ANOVA showed a trend toward significance $(p=0.082 ; n=10)$, suggesting that NS-evoked inhibition may also be reduced by VTA baclofen injection.

The major behavioral effect of VTA baclofen injection was a reduction in responding to the DS (Fig. $2 \mathrm{~A}$ ). Both incentive cue excitations and inhibitions are smaller when the animal fails to make a behavioral response to the DS than when the animal makes an appropriate operant response (Nicola et al., 2004a). To determine whether the reduction in incentive cue excitation and inhibition caused by VTA baclofen injection was entirely dependent on the reduction in behavioral responding to the DS, we examined the excitations and inhibitions evoked by DSs to which the animal responded with a nose poke. (This analysis therefore excludes the majority of postinjection DSs, to which the animal did not respond.) Median histograms constructed from eight neurons with incentive cue excitation show that the postinjection DS-evoked excitation was smaller than the preinjection excitation (Fig. 5A), an effect that was significant when the excitations in the $1 \mathrm{sec}$ after the DS (relative to $10 \mathrm{sec}$ pre-DS baseline) were compared $(p<0.01)$ (Fig. $5 B$ ). Similar effects were observed for 10 neurons with incentive cue inhibition $(p<0.03)$ (Fig. $5 C, D)$. Thus, the reduction of incentive cue excitation and inhibition caused by VTA baclofen injection cannot simply be attributed to the reduction in cue responding. This finding is consistent with the idea that the attenuation of incentive cue excitation and/or 

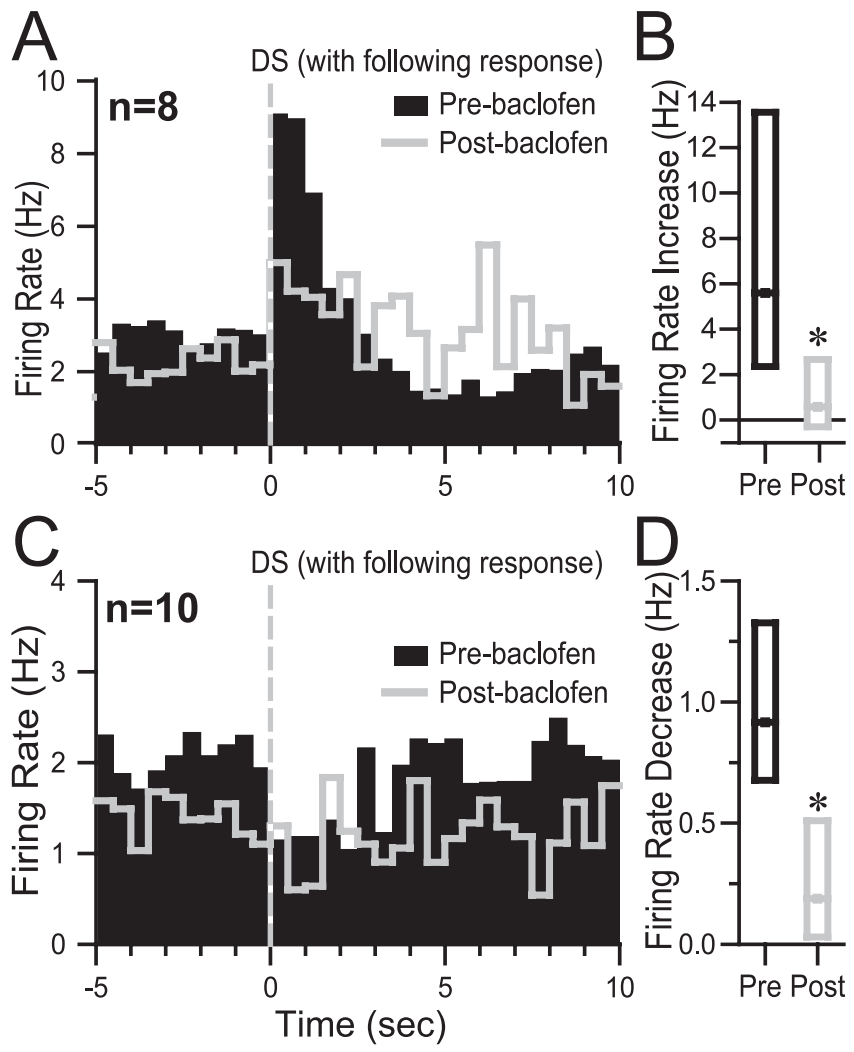

Figure 5. VTA baclofen injection reduces incentive cue excitation and inhibition when the animal makes a behavioral response to the DS. $A, C$, Median histograms compare excitation $(A)$ or inhibition $(C$ in response to the DS in the preinjection (black bars) and post-VTA baclofen injection (gray line) conditions; the analysis is limited to those DSs to which the animal made an operant response. $B, D$, Box plots show that the median excitation $(B)$ or inhibition $(D)$ is reduced after VTA baclofen injection (Post) compared with before the injection (Pre). ${ }^{*} p<0.05$ (Wilcoxon signed rank test).

inhibition was at least in part responsible for the reduction in behavioral responding to the DS.

In summary, VTA baclofen injection profoundly reduced the DS- and NS-evoked excitation and inhibition of NAc incentive cue-excited and -inhibited neurons and caused a trend toward a reduction in their baseline firing rate. These effects cannot be fully accounted for by the fact that animals respond to fewer DSs after VTA baclofen injection.

\section{Operant, receptacle entry, and reward-associated excitations and inhibitions}

Phasic excitations and inhibitions of NAc neurons are associated with every identifiable task event subsequent to DS presentation: nose-poke response, entry into the reward receptacle, reward consumption, and exit from the reward receptacle (Nicola et al., 2004a,b). We determined whether VTA baclofen injection affected these firing patterns. Figure 6 shows median histograms indicating that the magnitude of operant excitation, operant inhibition, receptacle entry excitation, sustained receptacle excitation, and sustained receptacle inhibition were all unaffected by behaviorally effective VTA baclofen injection (Table 1). The baseline firing rates of neurons with operant excitations and inhibitions were significantly reduced (Fig. 6A,B; Table 1).

\section{Receptacle exit excitations}

Phasic excitations signal the animal's exit from the reward receptacle in some NAc neurons. In a subpopulation of these neurons, the excitation is sustained and correlated with a reduced rate of
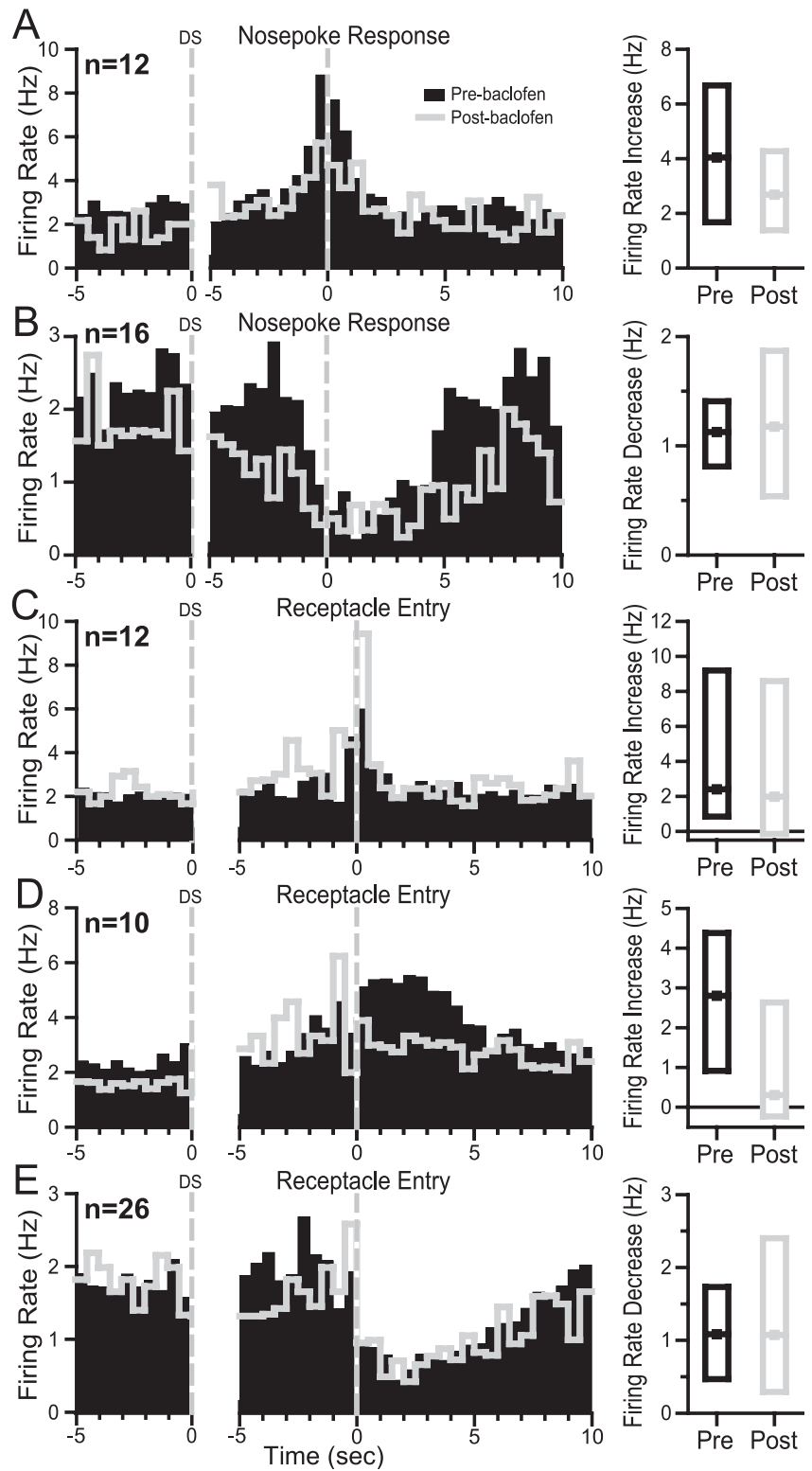

Figure 6. Behaviorally effective VTA baclofen injection has no effect on operant- and rewardrelated neural firing. Each panel shows histograms time locked to two events: on the left, 5 sec pre-DS baseline is shown, and on the right, the 5 sec before and 10 sec after the nose-poke response $(A, B)$ or reward receptacle entry $(C-E)$ is shown. Black bars are from the preinjection condition, and gray lines are during behaviorally effective VTA baclofen injections. Five response types are shown: $A$, operant excitation; $B$, operant inhibition; $C$, receptacle entry excitation; $D$, sustained receptacle excitation; $E$, sustained receptacle inhibition. To the right of each set of histograms are box plots showing the median excitation or inhibition (as well as the 1st and 3rd quartiles of the distribution of excitationsinhibitions). These were computed relative to the 10 sec pre-DS baseline using the analysis windows shown in Table 1.

uncued operant responding (Nicola et al., 2004b). The magnitude of the initial receptacle exit excitation was substantially reduced after behaviorally effective VTA baclofen injection, as shown in the example (Fig. 7A) and in median histograms (Fig. $7 B$ ) and box plots (Fig. 7D) summarizing the effect in nine neurons. The baseline firing rate was not affected by VTA baclofen injection (Fig. $7 B, C$; Table 1). Injection of saline into the VTA had no effects on receptacle exit excitation $(p>0.2)$ or on the baseline firing rate $(p>0.6)$ of 12 neurons (Fig. $7 E-H)$. 
Electrode and cannula placements

The tips of microinjection cannulas used for the NAc microinjection experiments were all within the NAc (Fig. $8 A$ ). The recording electrodes used for the VTA microinjectionNAc electrophysiology experiment were also within the NAc and were distributed similarly to the NAc injection cannulas (Fig. $8 B)$. Microinjection cannulas used for the VTA microinjection-NAc electrophysiology experiment were within the rostral VTA (Fig. 8C).

\section{Discussion}

Microinjection of $\mathrm{D}_{1}$ or $\mathrm{D}_{2}$ receptor antagonists into the NAc substantially reduced operant responding to reward-predictive cues. Therefore, NAc dopamine must affect the firing of at least one subpopulation of NAc neurons, and this effect on firing must contribute to the behavioral response to cues. VTA baclofen injection reduces NAc dopamine release (Tanner, 1979; Westerink et al., 1996) and should therefore produce effects similar to those of NAc dopamine antagonism. In fact, the behavioral effects of VTA baclofen injection and NAc dopamine receptor antagonism were strikingly similar. The most dramatic effects of VTA baclofen on NAc neuronal firing patterns were a reduction in incentive cue excitation and inhibition (and receptacle exit excitations). Phasic excitations and inhibitions associated with operant and consummatory behaviors were not affected by VTA baclofen injection. Thus, the only phasic firing patterns that both preceded the goal-directed behavior and were reduced by VTA baclofen were incentive cue excitations and inhibitions. These results strongly suggest that NAc cue-evoked excitations and inhibitions depend on dopamine and are required for the animal's goal-directed behavioral response to cues.

Neurons with incentive cue excitations and inhibitions exhibit critical properties that are consistent with the interpretation that their firing promotes a specific behavioral response to cues. Incentive cue excitations and inhibitions are triggered at short latency by predictive cues and are often sustained throughout the behavior required to obtain the reward predicted by the cue. These changes in firing are larger in response to reward-predictive cues than non-predictive cues (Ghitza et al., 2003; Nicola et al., 2004a) and larger when the animal makes a behavioral response than when no response is made or when the behavioral response occurs at very long latency (Nicola et al., 2004a). After VTA baclofen injection, these cue-elicited excitations and inhibitions were
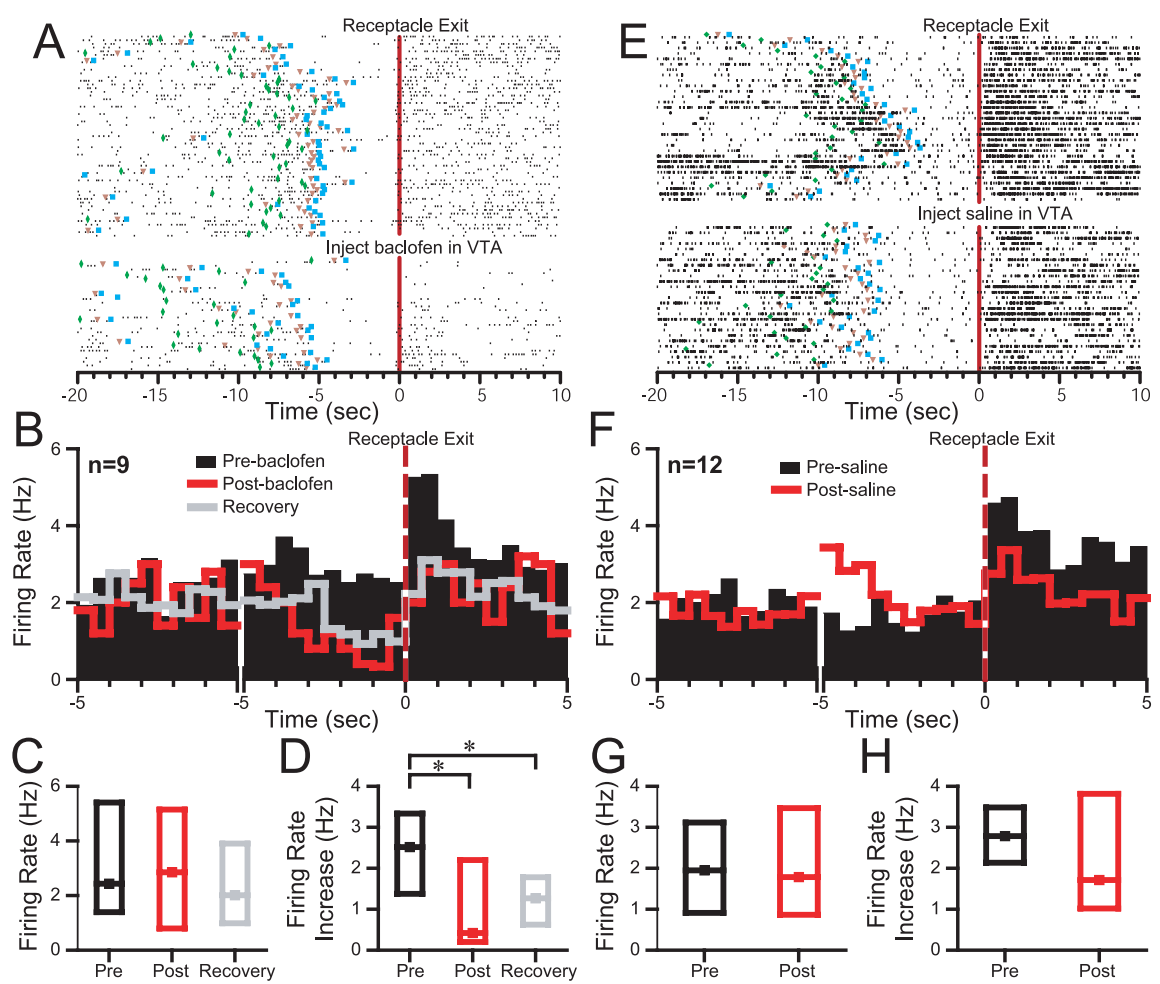

H

Figure 7. Behaviorally effective VTA baclofen injection reduces receptacle exit excitation but does not affect the baseline firing rate of receptacle exit excited neurons. $A$, Raster plot showing typical effects of VTA baclofen on an NAc neuron with receptacle exit excitation. The rasters are time locked to DS presentation and are sorted from top to bottom by time since the start of the session. VTA baclofen injection reduces the excitation occurring immediately after receptacle exit. This neuron also exhibited sustained receptacle excitation, which was unaffected by VTA baclofen. Dark green diamonds indicate the time of DS onset, orange triangles indicate the time at which the nose poke occurred, and blue squares indicate the reward receptacle entry. $B$, Each bin in the perievent histograms shows the median firing rate of all neurons with incentive cue excitations that were subjected to the three conditions: preinjection (black histogram), postinjection (red histogram), and behavioral recovery (gray histogram). Histograms on the left are time locked to DS presentation; on the right they show the 5 sec before and 5 sec after the receptacle exit. C, Box plots show the median (dot) and first and third quartiles (bottom and top box edges) of the baseline firing rate of the neurons shown in $B$ under the three conditions. D, Box plots show the median receptacle exit excitation under the three conditions. E, A typical receptacle exit excitation before and after saline injection in the VTA. F, Histograms show the median firing rate across all neurons with receptacle exit excitation that were recorded before and after VTA saline injection. $G$, Box plots show that the baseline firing rate was similar before and after VTA saline. $H$, The median receptacle exit excitation was also similar before and after VTA saline. ${ }^{*} p<0.05$ (SNK test).
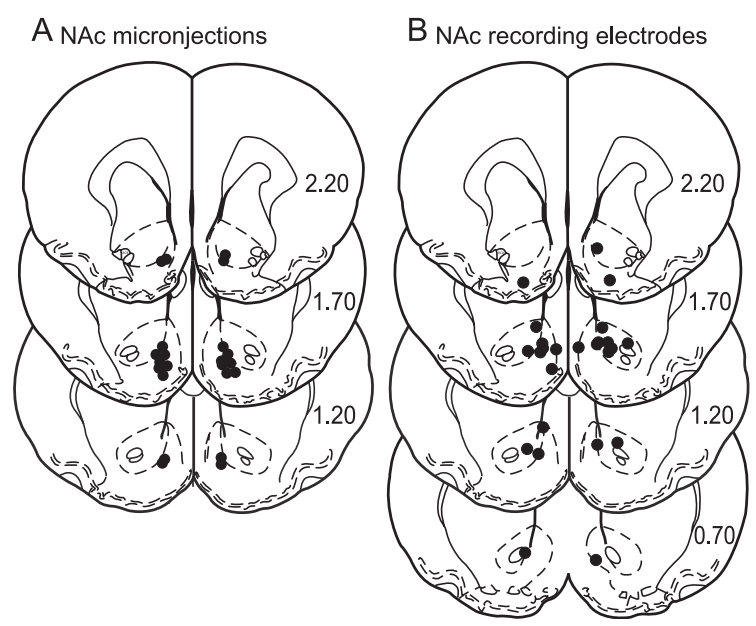

\section{VTA microinjections}

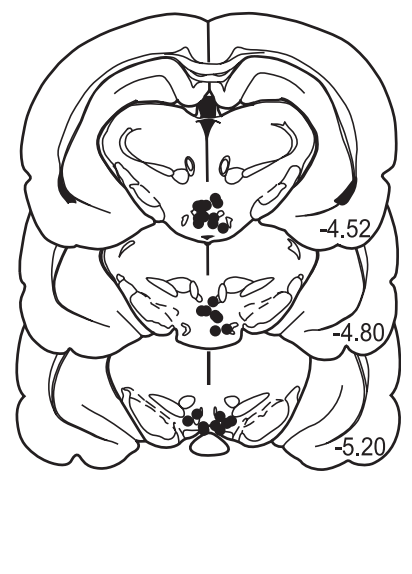

Figure 8. Recording and injection sites. $A$, Diagram shows the locations of the injector tips for the NAc microinjection behavioral experiment. $B$, Diagram shows the approximate center of each electrode array used for the VTA baclofen injection-NAC electrophysiology experiment. C, Diagram shows the locations of the injector tips for the VTA baclofen injection-NAc electrophysiology experiment. Numbers on each section indicate the distance anterior to bregma (in millimeters) according to Paxinos and Watson (1998). 
dramatically reduced at the same time that behavioral responding was severely impaired. The most parsimonious interpretation is that the direct VTA to NAc dopamine projection is required for these firing patterns and that the firing of these NAc neurons is required for the animal to perform the initial phase(s) of the cue response (orienting, approach, and subsequent nose poke).

One alternative interpretation is that a projection from the VTA to another nucleus affects the probability and latency of the behavioral response, and thus the VTA affects cue-elicited firing patterns in the NAc indirectly. For example, VTA dopamine neurons project to the prefrontal cortex and basolateral amygdala, both of which innervate the NAc. Indeed, the basolateral amygdala is required to respond to DSs under some conditions (Kantak et al., 2002; Yun and Fields, 2003). VTA baclofen injection undoubtedly reduced dopamine release in these nuclei as well as the NAc, and therefore it is conceivable that the reduction in incentive cue excitation and inhibition was attributable, in part, to a change in firing in afferent structures other than the VTA. However, the fact that injection of dopamine receptor antagonists into the NAc profoundly reduced cue responding means that the firing of at least one subpopulation of NAc neurons is both dopamine dependent and necessary for the performance of the task. Because VTA baclofen injection reduces NAc dopamine (Tanner, 1979; Westerink et al., 1996), it should also affect those firing patterns that are dopamine dependent. Even if the effects on firing caused by VTA baclofen injection were partly attributable to the altered firing of neurons in other nuclei that project to the NAc, it is unlikely that reduction of dopamine release in the NAc (a major target of VTA dopamine neurons) contributed nothing to the observed effects on firing. Similarly, another alternative interpretation, that inhibition of the GABAergic projection from the VTA to the NAc (Van Bockstaele and Pickel, 1995) is responsible for the observed effects of VTA baclofen injection on NAc neuronal firing, is not supported by the similarity of the behavioral effects of VTA baclofen injection and NAc dopamine receptor antagonism. Thus, although it remains a formal possibility that dopamine receptor antagonism in the NAc had its behavioral effects by changing some aspect of NAc neuronal firing not measured by our electrodes after VTA baclofen injection, the profound reduction of incentive cue excitations and inhibitions by VTA baclofen injection, together with the fact that they are tightly time locked to the cue onset and both encode the predictive value of the cue and the probability of a behavioral response, suggest that these firing patterns are dopamine dependent and promote the behavioral response to predictive cues.

VTA baclofen injection reduced the baseline firing rate of neurons with operant excitation and inhibition. These effects could have resulted in reduced DS responding if the tonic firing of NAc neurons is permissive for the behavior. However, this possibility is not supported by previous studies of the effects of dopamine iontophoresis onto NAc and striatal neurons in awake animals, which showed that dopamine application reduced (Rolls et al., 1984; Kiyatkin and Rebec, 1996) or did not consistently change (Inase et al., 1997) the baseline firing rate, in contrast to our observations that inactivating dopamine neurons reduced baseline firing of some neurons. The iontophoretically applied dopamine should mimic tonically released dopamine because, in these studies, the dopamine was applied for prolonged periods of time. Therefore, although a permissive role for tonic NAc neuronal firing cannot be definitively ruled out, the available evidence is most consistent with the idea that incentive cue excitations and/or inhibitions are dopamine dependent and required for the behavioral response to predictive cues.

VTA baclofen injection caused a trend toward a reduction of the baseline firing rate of neurons with incentive cue excitations and inhibitions. This raises the question of whether the reduction in baseline rate prevented further excitation or inhibition by ceiling or floor effects. However, the reduction in baseline firing rate was clearly smaller (as a proportion of the preinjection baseline rate) than the reduction in cue-evoked excitation and inhibition (Table 1). Furthermore, neurons with operant excitations and inhibitions, whose baseline firing was reduced by VTA baclofen injection, exhibited normal event-related phasic excitations and inhibitions, and receptacle exit excitations were reduced without a corresponding reduction in baseline firing. A more likely hypothesis is that the phasic firing patterns that were dependent on the VTA (incentive cue excitation and inhibition, and receptacle exit excitation) were dependent on the phasic release of dopamine. This possibility is consistent with the properties of midbrain dopamine neurons, which fire short bursts in response to predictive cues (Ljungberg et al., 1992; Schultz et al., 1993). Recent measurements of phasic dopamine release in awake animals indicate that predictive cues do in fact cause the rapid release of dopamine within the NAc (Robinson et al., 2001, 2002; Roitman et al., 2004), suggesting that DS presentation increased NAc dopamine release rapidly and transiently.

That the cue-evoked firing responses of NAc neurons depend on dopamine is supported by previous findings that the phasic responses to cues of primate striatal tonically active neurons (TANs) are abolished by depletion of dopamine from the striatum (Aosaki et al., 1994). Although our neurons are not likely to be TANs (Nicola et al., 2004a), dopamine could exert similar response-enhancing effects on NAc projection neurons. This idea is further supported by findings of dopamine-mediated enhancement of evoked versus baseline firing rate in striatal (Rolls et al., 1984; Kiyatkin and Rebec, 1996) and prefrontal cortical (Sawaguchi et al., 1986, 1988, 1990; Sawaguchi, 1987) neurons recorded in behaving animals. A number of cellular mechanisms could underlie such enhancement of incentive cue excitation (Gonon and Sundstrom, 1996; Gonon, 1997; Hernandez-Lopez et al., 1997; Nicola and Malenka, 1997; Nicola et al., 2000; West and Grace, 2002; Hopf et al., 2003; O'Donnell, 2003). Dopamine-mediated enhancement of incentive cue inhibition could result from enhancement of incentive cue excitation in neurons that exert collateral inhibition onto incentive cue-inhibited neurons or from direct inhibitory effects of dopamine on excitatory synaptic transmission (Harvey and Lacey, 1996; Nicola et al., 1996; Nicola and Malenka, 1998).

Although VTA baclofen injection reduced receptacle exit excitations, this effect is not likely to explain the reduced cue responding, because these excitations did not precede the operant response. Because a subset of these excitations last for tens of seconds after the exit, and this prolonged excitation is correlated with decreased uncued operant responding (Nicola et al., 2004b), these excitations may actively inhibit the operant response in the absence of the DS. Therefore, the effect of dopamine released at receptacle exit may be to facilitate the switch between consummatory and other behaviors, consistent with proposals for a role of dopamine in the basal ganglia in switching from ongoing behavior to behaviors that are more beneficial given the changing environmental conditions (Oades, 1985; Redgrave et al., 1999). Thus, the VTA dependence of incentive cue excitation and inhibition and receptacle exit excitation suggests that these firing 
patterns are the critical dopamine-dependent elements within the NAc that are necessary to promote the behavioral response to predictive environmental information.

In summary, both VTA baclofen injection and NAc dopamine receptor antagonism reduced operant responding to a predictive cue. The most prominent effects on NAc neuronal firing caused by VTA baclofen injection were a reduction in the excitation and inhibition evoked by the cue. These results strongly suggest that incentive cue excitations and inhibitions are dopamine dependent and facilitate the goal-directed behavioral response to cues.

\section{References}

Ahlenius S, Briem S, Hillegaart V, Magnusson O (1990) Diffusion and absorption of $(-)$ sulpiride and raclopride after intracerebral administration in the rat. Biochem Pharmacol 39:2066-2069.

Aosaki T, Graybiel AM, Kimura M (1994) Effect of the nigrostriatal dopamine system on acquired neural responses in the striatum of behaving monkeys. Science 265:412-415.

Apicella P, Ljungberg T, Scarnati E, Schultz W (1991) Responses to reward in monkey dorsal and ventral striatum. Exp Brain Res 85:491-500.

Bassareo V, Di Chiara G (1999) Differential responsiveness of dopamine transmission to food-stimuli in nucleus accumbens shell/core compartments. Neuroscience 89:637-641.

Berridge KC, Robinson TE (1998) What is the role of dopamine in reward: hedonic impact, reward learning, or incentive salience? Brain Res Brain Res Rev 28:309-369.

Blackburn JR, Pfaus JG, Phillips AG (1992) Dopamine functions in appetitive and defensive behaviours. Prog Neurobiol 39:247-279.

Bowman EM, Aigner TG, Richmond BJ (1996) Neural signals in the monkey ventral striatum related to motivation for juice and cocaine rewards. J Neurophysiol 75:1061-1073.

Carelli RM, Deadwyler SA (1994) A comparison of nucleus accumbens neuronal firing patterns during cocaine self-administration and water reinforcement in rats. J Neurosci 14:7735-7746.

Carlezon Jr WA, Haile CN, Coppersmith R, Hayashi Y, Malinow R, Neve RL, Nestler EJ (2000) Distinct sites of opiate reward and aversion within the midbrain identified using a herpes simplex virus vector expressing GluR1. J Neurosci 20:RC62(1-5).

Chang JY, Sawyer SF, Lee RS, Woodward DJ (1994) Electrophysiological and pharmacological evidence for the role of the nucleus accumbens in cocaine self-administration in freely moving rats. J Neurosci 14:1224-1244.

Cromwell HC, Schultz W (2003) Effects of expectations for different reward magnitudes on neuronal activity in primate striatum. J Neurophysiol 89:2823-2838.

Di Ciano P, Cardinal RN, Cowell RA, Little SJ, Everitt BJ (2001) Differential involvement of NMDA, AMPA/kainate, and dopamine receptors in the nucleus accumbens core in the acquisition and performance of pavlovian approach behavior. J Neurosci 21:9471-9477.

Erhardt S, Mathe JM, Chergui K, Engberg G, Svensson TH (2002) GABA(B) receptor-mediated modulation of the firing pattern of ventral tegmental area dopamine neurons in vivo. Naunyn Schmiedebergs Arch Pharmacol 365:173-180.

Ghitza UE, Fabbricatore AT, Prokopenko V, Pawlak AP, West MO (2003) Persistent cue-evoked activity of accumbens neurons after prolonged abstinence from self-administered cocaine. J Neurosci 23:7239-7245.

Gonon F (1997) Prolonged and extrasynaptic excitatory action of dopamine mediated by $\mathrm{D}_{1}$ receptors in the rat striatum in vivo. J Neurosci 17:5972-5978.

Gonon F, Sundstrom L (1996) Excitatory effects of dopamine released by impulse flow in the rat nucleus accumbens in vivo. Neuroscience 75:13-18.

Harvey J, Lacey MG (1996) Endogenous and exogenous dopamine depress EPSCs in rat nucleus accumbens in vitro via D1 receptors activation. J Physiol (Lond) 492:143-154.

Hassani OK, Cromwell HC, Schultz W (2001) Influence of expectation of different rewards on behavior-related neuronal activity in the striatum. J Neurophysiol 85:2477-2489.

Hernandez-Lopez S, Bargas J, Surmeier DJ, Reyes A, Galarraga E (1997) $D_{1}$ receptor activation enhances evoked discharge in neostriatal medium spiny neurons by modulating an L-type $\mathrm{Ca}^{2+}$ conductance. J Neurosci 17:3334-3342.

Hollerman JR, Tremblay L, Schultz W (1998) Influence of reward expectation on behavior-related neuronal activity in primate striatum. J Neurophysiol 80:947-963.

Hopf FW, Cascini MG, Gordon AS, Diamond I, Bonci A (2003) Cooperative activation of dopamine $D_{1}$ and $D_{2}$ receptors increases spike firing of nucleus accumbens neurons via G-protein $\beta \gamma$ subunits. J Neurosci 23:5079-5087.

Ikemoto S, Murphy JM, McBride WJ (1998) Regional differences within the rat ventral tegmental area for muscimol self-infusions. Pharmacol Biochem Behav 61:87-92.

Inase M, Li BM, Tanji J (1997) Dopaminergic modulation of neuronal activity in the monkey putamen through D1 and D2 receptors during a delayed Go/Nogo task. Exp Brain Res 117:207-218.

Johnson SW, North RA (1992) Two types of neurone in the rat ventral tegmental area and their synaptic inputs. J Physiol (Lond) 450:455-468.

Kantak KM, Black Y, Valencia E, Green-Jordan K, Eichenbaum HB (2002) Dissociable effects of lidocaine inactivation of the rostral and caudal basolateral amygdala on the maintenance and reinstatement of cocaineseeking behavior in rats. J Neurosci 22:1126-1136.

Kiyatkin EA, Rebec GV (1996) Dopaminergic modulation of glutamateinduced excitations of neurons in the neostriatum and nucleus accumbens of awake, unrestrained rats. J Neurophysiol 75:142-153.

Lacey MG, Mercuri NB, North RA (1988) On the potassium conductance increase activated by GABAB and dopamine $\mathrm{D} 2$ receptors in rat substantia nigra neurones. J Physiol (Lond) 401:437-453.

Lacey MG, Mercuri NB, North RA (1989) Two cell types in rat substantia nigra zona compacta distinguished by membrane properties and the actions of dopamine and opioids. J Neurosci 9:1233-1241.

Ljungberg T, Apicella P, Schultz W (1992) Responses of monkey dopamine neurons during learning of behavioral reactions. J Neurophysiol 67:145-163.

McCullough LD, Salamone JD (1992) Involvement of nucleus accumbens dopamine in the motor activity induced by periodic food presentation: a microdialysis and behavioral study. Brain Res 592:29-36.

Mirenowicz J, Schultz W (1994) Importance of unpredictability for reward responses in primate dopamine neurons. J Neurophysiol 72:1024-1027.

Nicola SM, Deadwyler SA (2000) Firing rate of nucleus accumbens neurons is dopamine-dependent and reflects the timing of cocaine-seeking behavior in rats on a progressive ratio schedule of reinforcement. J Neurosci 20:5526-5537.

Nicola SM, Malenka RC (1997) Dopamine depresses excitatory and inhibitory synaptic transmission by distinct mechanisms in the nucleus accumbens. J Neurosci 17:5697-5710.

Nicola SM, Malenka RC (1998) Modulation of synaptic transmission by dopamine and norepinephrine in ventral but not dorsal striatum. J Neurophysiol 79:1768-1776.

Nicola SM, Kombian SB, Malenka RC (1996) Psychostimulants depress excitatory synaptic transmission in the nucleus accumbens via presynaptic $\mathrm{D}_{1}$-like dopamine receptors. J Neurosci 16:1591-1604.

Nicola SM, Surmeier J, Malenka RC (2000) Dopaminergic modulation of neuronal excitability in the striatum and nucleus accumbens. Annu Rev Neurosci 23:185-215.

Nicola SM, Yun IA, Wakabayashi KT, Fields HL (2004a) Cue-evoked firing of nucleus accumbens neurons encodes motivational significance during a discriminative stimulus task. J Neurophysiol 91:1840-1865.

Nicola SM, Yun IA, Wakabayashi KT, Fields HL (2004b) The firing of nucleus accumbens neurons during the consummatory phase of a discriminative stimulus task depends on previous reward predictive cues. J Neurophysiol 91:1866-1882.

Oades RD (1985) The role of noradrenaline in tuning and dopamine in switching between signals in the CNS. Neurosci Biobehav Rev 9:261-282.

O'Donnell P (2003) Dopamine gating of forebrain neural ensembles. Eur J Neurosci 17:429-435.

Paxinos G, Watson C (1998) The rat brain in stereotaxic coordinates, Ed 4. San Diego: Academic.

Peoples LL, West MO (1996) Phasic firing of single neurons in the rat nucleus accumbens correlated with the timing of intravenous cocaine selfadministration. J Neurosci 16:3459-3473.

Redgrave P, Prescott TJ, Gurney K (1999) The basal ganglia: a vertebrate solution to the selection problem? Neuroscience 89:1009-1023. 
Robinson DL, Phillips PE, Budygin EA, Trafton BJ, Garris PA, Wightman RM (2001) Sub-second changes in accumbal dopamine during sexual behavior in male rats. NeuroReport 12:2549-2552.

Robinson DL, Heien ML, Wightman RM (2002) Frequency of dopamine concentration transients increases in dorsal and ventral striatum of male rats during introduction of conspecifics. J Neurosci 22:10477-10486.

Roitman MF, Stuber GD, Phillips PE, Wightman RM, Carelli RM (2004) Dopamine operates as a subsecond modulator of food seeking. J Neurosci 24:1265-1271.

Rolls ET, Thorpe SJ, Boytim M, Szabo I, Perrett DI (1984) Responses of striatal neurons in the behaving monkey. 3. Effects of iontophoretically applied dopamine on normal responsiveness. Neuroscience 12:1201-1212.

Sawaguchi T (1987) Catecholamine sensitivities of neurons related to a visual reaction time task in the monkey prefrontal cortex. J Neurophysiol $58: 1100-1122$.

Sawaguchi T, Matsumura M, Kubota K (1986) Dopamine modulates neuronal activities related to motor performance in the monkey prefrontal cortex. Brain Res 371:404-408.

Sawaguchi T, Matsumura M, Kubota K (1988) Dopamine enhances the neuronal activity of spatial short-term memory task in the primate prefrontal cortex. Neurosci Res 5:465-473.

Sawaguchi T, Matsumura M, Kubota K (1990) Catecholaminergic effects on neuronal activity related to a delayed response task in monkey prefrontal cortex. J Neurophysiol 63:1385-1400.

Schultz W, Apicella P, Scarnati E, Ljungberg T (1992) Neuronal activity in monkey ventral striatum related to the expectation of reward. J Neurosci 12:4595-4610.

Schultz W, Apicella P, Ljungberg T (1993) Responses of monkey dopamine neurons to reward and conditioned stimuli during successive steps of learning a delayed response task. J Neurosci 13:900-913.

Seutin V, Johnson SW, North RA (1993) Apamin increases NMDA-induced burst-firing of rat mesencephalic dopamine neurons. Brain Res 630:341-344.

Shidara M, Aigner TG, Richmond BJ (1998) Neuronal signals in the monkey ventral striatum related to progress through a predictable series of trials. J Neurosci 18:2613-2625.
Tanner T (1979) GABA-induced locomotor activity in the rat, after bilateral injection into the ventral tegmental area. Neuropharmacology 18:441-446.

Taylor JR, Robbins TW (1986) 6-Hydroxydopamine lesions of the nucleus accumbens, but not of the caudate nucleus, attenuate enhanced responding with reward-related stimuli produced by intra-accumbens $d$-amphetamine. Psychopharmacology (Berl) 90:390-397.

Van Bockstaele EJ, Pickel VM (1995) GABA-containing neurons in the ventral tegmental area project to the nucleus accumbens in rat brain. Brain Res 682:215-221.

Wakabayashi KT, Fields HL, Nicola SM (2004) Dissociation of the role of nucleus accumbens dopamine in responding to reward-predictive cues and waiting for reward. Behav Brain Res, in press.

Weiss F, Maldonado-Vlaar CS, Parsons LH, Kerr TM, Smith DL, Ben-Shahar O (2000) Control of cocaine-seeking behavior by drug-associated stimuli in rats: effects on recovery of extinguished operant-responding and extracellular dopamine levels in amygdala and nucleus accumbens. Proc Natl Acad Sci USA 97:4321-4326.

West AR, Grace AA (2002) Opposite influences of endogenous dopamine $D_{1}$ and $D_{2}$ receptor activation on activity states and electrophysiological properties of striatal neurons: studies combining in vivo intracellular recordings and reverse microdialysis. J Neurosci 22:294-304.

Westerink BH, Kwint HF, deVries JB (1996) The pharmacology of mesolimbic dopamine neurons: a dual-probe microdialysis study in the ventral tegmental area and nucleus accumbens of the rat brain. J Neurosci 16:2605-2611.

Wolterink G, Phillips G, Cador M, Donselaar-Wolterink I, Robbins TW, Everitt BJ (1993) Relative roles of ventral striatal D1 and D2 dopamine receptors in responding with conditioned reinforcement. Psychopharmacology (Berl) 110:355-364.

Wyvell CL, Berridge KC (2000) Intra-accumbens amphetamine increases the conditioned incentive salience of sucrose reward: enhancement of reward "wanting" without enhanced "liking" or response reinforcement. J Neurosci 20:8122-8130.

Yun IA, Fields HL (2003) Basolateral amygdala lesions impair both cue- and cocaine-induced reinstatement in animals trained on a discriminative stimulus task. Neuroscience 121:747-757. 